\title{
Cardiac Evaluation of Patients with Chronic Obstructive Pulmonary Disease using Electrocardiogram with Special Reference to Severity and Duration in a Tertiary Care Centre
}

\author{
Lokesh $\mathbf{S}^{1}$, Laxmish Naik ${ }^{2}$ \\ ${ }^{1}$ Associate Professor, Department of General Medicine, Vydehi Institute of Medical Sciences and Research Centre, Bengaluru, \\ ${ }^{2}$ Consultant Physician, General Hospital, Bhatkal, Uttara Kannada-581320
}

Corresponding author: Dr. Lokesh S, No-A-19, Vydehi Staff Quarters, A-Block, Vydehi Hospital Campus, EPIP Area, Whitefield, Bengaluru-560066, Karnataka, India

DOI: 10.21276/ijcmsr.2018.3.3.22

How to cite this article: Lokesh S, Laxmish Naik. Cardiac evaluation of patients with chronic obstructive pulmonary disease using electrocardiogram with special reference to severity and duration in a tertiary care centre. International Journal of Contemporary Medicine Surgery and Radiology. 2018;3(3):C101-C104.

\section{A B S T R A C T}

Introduction: Cardiovascular system involvement in chronic obstructive pulmonary disease is a well known fact. Among which right ventricular dysfunction and pulmonary vascular disease are common. These cardiovascular changes can be detected early with electrocardiogram and helps in reducing mortality and morbidity. Present study was aimed at studying the diagnostic values of Electrocardiographic findings in chronic obstructive pulmonary disease patient and to correlate the electrocardiographic changes with respect to duration and severity of the disease.

Material and methods: In this study fifty patients clinically and spirometrically proven chronic obstructive pulmonary disease patients admitted between January 2013 to December 2013 in the Department of general medicine and Department of Pulmonary medicine at Vydehi institute of medical sciences were selected. All the patients selected were subjected to relevant investigations including electrocardiography and they were further classified based on GOLD guidelines. The Chisquare test is applied to find out the significance

Results: Out of 50 patients majority of them were males $86 \%$ and females were $14 \%$ with predominant distribution in the age group of 51-60 years. Totally $46 \%$ of patients had ECG features suggestive of Right ventricular hypertrophy out of which all had right axis deviation. Other features were $\mathrm{P}$ pulmonale which indicates pulmonary hypertension was seen in $50 \%$, poor $\mathrm{R}$ wave progression in $22 \%$ and low voltage complex in $18 \%$ of patients. P pulmonale, Right ventricular hypertrophy and Right axis deviation correlates significantly with severity of the disease and only P pulmonale varies significantly with duration of the disease.

Conclusion: From this study we conclude that electrocardiographic changes like right ventricular hypertrophy, P pulmonale and right axis deviation correlate with severity of chronic obstructive pulmonary disease. Electrocardiogram being a simple, non invasive, relatively cheaper and widely available investigation, it is worthwhile to subject all the chronic obstructive pulmonary disease patients for the same to diagnose the complications early and reduce mortality and morbidity.

Key words: COPD, P-pulmonale, Right Ventricular Hypertrophy, Spirometry

\section{INTRODUCTION}

According to GOLD 2018, Chronic Obstructive Pulmonary Disease is defined as a common, preventable and treatable disease that is characterized by persistent respiratory symptoms and airflow limitation that is due to airway and/or alveolar abnormalities usually caused by significant exposure to noxious particles or gases.

It is an underdiagnosed and life threatening lung disease which is currently fourth leading cause of death and also projected to be the third leading cause of death by $2020{ }^{1}$

It is a known fact that respiratory system and cardiovascular system are closely intertwined. Any changes in respiratory system can affect cardiovascular system and vice versa. Many earlier studies have shown association of many cardiovascular features with COPD and these changes can be demonstrated Electrocardiographically. Commonly encountered electrocardiographic changes in COPD include $\mathrm{P}$-pulmonale, low voltage complex, sinus tachycardia, right bundle branch block etc. ${ }^{2,3}$ Electrocardiogram being a simple, noninvasive and easily available bedside investigation, it can be utilized to identify early cardiovascular complications in chronic obstructive pulmonary diseases and thereby help to prevent morbidity and mortality.

The present study was conducted with the aim of studying the diagnostic values of ECG findings in COPD patients. Further, an attempt has been made to correlate the electrocardiographic changes with respect to duration and severity of the disease. 


\section{MATERIAL AND METHODS}

This was an observational and prospective clinical study. 50 patients admitted in the Department of General medicine and Department of Respiratory medicine of Vydehi institute of medical sciences and research centre, Bengaluru during the period of January 2013 to December 2013, who were fitting into the inclusion criteria were included in the study. Institutional ethical committee clearance was obtained and informed consent was taken from all the patients. All the patients who were spirometrically proven chronic obstructive pulmonary disease who were above 18 years were included for the study. Patients with Bronchial asthma, Tuberculosis, Ischemic Heart Disease, Rheumatic Heart Disease, Thyrotoxicosis were excluded from the study

All patients in the study underwent a full clinical evaluation. Relevant Clinical history and physical examination findings were recorded. All patients underwent biochemical tests, like complete blood counts, Renal function tests, Random blood sugars. All patients were subjected to PFT using spirometric evaluation of: Forced expiratory volume in one second $\left(\mathrm{FEV}_{1}\right)$, Forced vital capacity (FVC), Ratio of $\mathrm{FEV}_{1} / \mathrm{FVC}$ ratio. The best of the three attempts were taken. Severity of COPD was classified according to GOLD criteria.

A 12 lead ECG was taken in all the patients under study and analyzed for Right ventricular hypertrophy, P-pulmonale, Poor progression of $\mathrm{R}$ wave, Low voltage complex and Incomplete Right bundle branch block.

\section{STATISTICAL ANALYSIS}

All the data was analyzed using IBM SPSS software and expressed in the form of numbers and percentage. Chisquare test was used to establish the significance level between groups. $P$ value of $<0.05$ was considered as significant.

\section{RESULTS}

In the present study totally 50 patients were enrolled, among which 43 were males and 7 patients were females. The mean age was $57.48 \pm 8.13$ years. Range was between $44-74$ years. Maximum numbers of patients are between 51-60years
(40\%). Mean duration of symptoms was $6.12 \pm 4.5$ years. Most of the patients presented with symptoms for less than 5years. Only $14 \%$ had symptoms for more than 10 years. Based on GOLD criteria all the patients were classified into mild, moderate, severe and very severe. There were no patients in the mild group. Majority were in the severe group of $44 \%$ followed by $34 \%$ in very severe group and $22 \%$ in moderate group. 86 percent of the patients were smokers. All patients presented with breathlessness and cough with expectoration. $40 \%$ of patients presented with swelling of both legs and $12 \%$ had fever.

Most common clinical finding was tachypnea (70\%) followed by loud P2 (54\%). 36\% were diagnosed as cor pulmonale by clinical examination. They had features like raised JVP, bilateral pitting pedal edema, epigastric pulsations. Totally 23 patients had ECG features suggestive of Right ventricular hypertrophy out of which all had right axis deviation. So the Corpulmonale diagnosed by ECG was 46\%. The most common RVH criteria present was Right axis deviation followed by R/S ratio in V1>1 and R/S ratio $<1$ in V5/V6. Other features were $\mathrm{P}$ pulmonale which indicates pulmonary hypertension was $50 \%$ and poor $\mathrm{R}$ wave progression in $22 \%$ and low voltage complex in $18 \%$ of patients.

$\mathrm{P}$ pulmonale was seen in $36 \%$ of moderate degree COPD patients, $22 \%$ of severe degree and $94 \%$ very severe patients. Right axis deviation is seen in $27 \%$ of moderate degree, $31 \%$ of severe degree and $88 \%$ of very severe degree patients. $\mathrm{RVH}$ is seen in $36 \%$ of moderate degree, $27 \%$ of severe degree and $76 \%$ of very severe degree patients. $\mathrm{P}$ pulmonale, Right ventricular hypertrophy and Right axis deviation correlates significantly with severity of the disease $(\mathrm{p}<0.05)$ (Table 1$)$.

The most common ECG change found in patients with less than 5 years duration was Right ventricular hypertrophy (36\%). In patients with 5-10 years duration group $\mathrm{P}$ pulmonale and Right axis deviation was found equally in $72 \%$ of patients. However in COPD patients of more than 10 years duration group Right axis deviation is the most common finding. Among all these findings only p pulmonale varies significantly with duration of the disease with $P$ value less than 0.05 .

\begin{tabular}{|c|c|c|c|c|c|c|c|c|c|}
\hline \multirow[t]{2}{*}{ ECG findings } & \multirow[t]{2}{*}{ Mild=0 } & \multicolumn{2}{|c|}{ Moderate $(n=11)$} & \multicolumn{2}{|c|}{ Severe $(n=22)$} & \multicolumn{2}{|c|}{ V. severe $(n=17)$} & \multirow[t]{2}{*}{ Chi square } & \multirow[t]{2}{*}{$P$ value } \\
\hline & & No. & $\%$ & No. & $\%$ & No. & $\%$ & & \\
\hline P pulmonale & 0 & 4 & 36 & 5 & 22 & 16 & 94 & 20.59 & $<0.01$ \\
\hline $\mathrm{RVH}$ & 0 & 4 & 36 & 6 & 27 & 13 & 76 & 18.54 & $<0.01$ \\
\hline RAD & 0 & 3 & 27 & 7 & 31 & 15 & 88 & 15.12 & $<0.01$ \\
\hline Low voltage complex & 0 & 1 & 9 & 5 & 22 & - & - & 4.80 & 0.09 \\
\hline Poor progression of ' $r$ ' wave & 0 & 4 & 36 & 6 & 27 & 1 & 5.8 & 4.25 & 0.11 \\
\hline Incomplete RBBB & 0 & - & & 2 & 9 & 2 & 11 & 1.31 & 0.51 \\
\hline
\end{tabular}

\begin{tabular}{|l|c|c|c|}
\hline ECG changes & Padmavati and Raizada $^{\mathbf{1 1}}$ & Murphy and Hutcheson $^{\mathbf{9}}$ & Present study $^{5}$ \\
\hline P pulmonale & 95 & 26.4 & 30 \\
\hline R/S in V1>1 & - & 7.5 & 17 \\
\hline R $>$ 7mm in V1 & 2.6 & 9.4 & 5 \\
\hline Incomplete RBBB & 12.9 & 2 & 18 \\
\hline Low voltage complex & 41 & 58.5 & \\
\hline \multicolumn{2}{|c|}{ Table-2: Comparison ECG findings-in percentage with other studies } \\
\hline
\end{tabular}




\section{DISCUSSION}

Cardiovascular involvement in the form of impairment of right ventricular function and pulmonary blood vessels are well known to complicate the clinical course of chronic obstructive pulmonary disease patients. These changes have got impact on the survival of COPD patients. ${ }^{4}$ These dysfunctions lead on to the changes in electrocardiogram pattern. Some of the ECG patterns reported are vertical axis for $\mathrm{P}$ and $\mathrm{QRS}$, increased amplitude of $\mathrm{P}$-wave, low voltage complexes, which may vary with class of GOLD classification and population. In this study we have attempted to correlate the ECG changes with the severity and duration of the COPD

In present study consisting of 50 patients of COPD maximum numbers of patient are in 51-60 years age group with mean age of $57.48 \pm 8$ years which was comparable to the study done by Burrows et al..$^{5}$ in which mean age was $56.5 \pm 7.4$ yrs and Himelmann et al. ${ }^{6}$ in which mean age was $66 \pm 6 y$ rs. Majority of the patients are males with $86 \%$ and $14 \%$ are females. This can be explained because of smoking habits in males which is an important risk factor for the development of COPD. Among all females none were smokers however all of them were exposed to biomass combustion gas. Predominance of male pattern was correlating with other studies done by Chappel A.G. ${ }^{7}$

Average duration of symptoms in the present study was $6.12 \pm 4.5 \mathrm{yrs}$. In the study conducted by Gupta et $\mathrm{a}^{8}{ }^{8}$ the mean duration of symptoms was $8.9 \pm 4.9$ yrs. $86 \%$ were smokers with $54 \%$ having smoking history of more than 15 cigarette pack years. The mean duration of smoking was $20.6 \pm 9.12$ cigarette pack years with range between 10 to 45 cigarette pack years. Present study correlates with the study done by Gupta and Khastgir study $26 \pm 16.1$ was the mean pack years of smoking. ${ }^{8}$

All patients in this study presented with complaints of cough with expectoration and breathlessness. 50\% of the patients had symptomatic duration of less than 5 years. $20 \%$ of the patients presented with complaints of leg swelling.

According to GOLD classification criteria $44 \%$ of the patients were in severe group. Totally $78 \%$ of the patients were in severe very severe group.

In the present study, $46 \%$ of the cases showed ECG findings suggestive of RVH. Present study correlates nearly with Murphy ML and Hutchenson. F $^{9}$ study where RVH was seen in $43.6 \%$ and Millard $\mathrm{FJC}^{10}$ study which shows RVH in $45.7 \%$ of patients.

Other ECG changes like $\mathrm{P}$ pulmonale, $\mathrm{R} / \mathrm{S}$ ratio in $\mathrm{V} 1>1$, $\mathrm{R}$-wave $>7 \mathrm{~mm}$ in $\mathrm{V} 1$, incomplete $\mathrm{RBBB}$ and low voltage complexes varies in different studies as follows(Table 2)

In the present study Right axis deviation, Right ventricular hypertrophy and $\mathrm{p}$ pulmonale correlates significantly with the severity of the disease. This means that the incidence of above ECG patterns increases significantly with increase in severity of the disease. Many studies had shown similar results. M. K. Tandon ${ }^{12}$ found increased incidence of RAD, $\mathrm{P}$-pulmonale and dominant $\mathrm{S}$ wave in V5/6 with increasing evidence of severity.

In the present study, $p$ pulmonale varies significantly $(\mathrm{p}<0.05)$ with the duration of the disease. That means as the duration of the disease increases chance of patient having $\mathrm{p}$ pulmonale increases. Other features like $\mathrm{RVH}$ and $\mathrm{RAD}$ are also increasing with the duration of the disease. However, they are statistically not significant. This can be due to majority of the patients in this study had duration of symptoms less than $5 \mathrm{yrs}(50 \%)$ and the percentage of patients above $10 \mathrm{yrs}$ of symptoms was only $14 \%$.

\section{Limitations}

Present study being single centre study it may not give the overall picture of the disease pattern. Hence it requires multi centric study to authenticate and one more limitation is the small sample size.

\section{CONCLUSION}

From this study we conclude that there is significant association found between ECG changes of right ventricular hypertrophy and right atrial hypertrophy with severity of COPD. Hence Electrocardiogram must be included in the initial evaluation of all the COPD patients, so that the complications like corpulmonale, pulmonary hypertension can be detected early and be treated and thereby reduce the morbidity and mortality.

\section{REFERENCE}

1. Global Initiative for Chronic Obstructive Lung Disease (GOLD). Global Strategy for the Diagnosis, Management and Prevention of Chronic obstructive pulmonary disease.2018. Available from: http://www. goldcopd.org/.

2. Calatayud JB,Abad JM,KhoiNB et al. P-wave changes in chronic obstructive pulmonary disease. Amer Heart J 1970;70(1):444

3. Scott RC. The electrocardiogram in pulmonary emphysema and chronic cor pulmonale. Amer Heart J 1961;61 (3):843

4. Jeremy A. Falk, Steven Kadiev, Gerard J. Criner, Steven M. Scharf et al. Cardiac Disease in Chronic Obstructive Pulmonary Disease. Proc Am Thorac Soc 2008; 5(2):543-548.

5. Benjamin Burrows, Louis J. Kettel, Albert H. Niden, Murray Rabinowitz, Carl F. Diener. Patterns of Cardiovascular dysufunction in chronic obstructive lung disease. N. Engl J Med. 1972;286 (17): 912-917.

6. Himelmann RB, Struve SN, Brown JK, Namnum P, Schiller NB. Improved recognition of corpulmonale in patients with severe chronic obstructive pulmonary disease. Am J. Med. 1988;84(5):891-898.

7. Chappel AG. The electrocardiogram in chronic bronchitis and emphysema. Br Heart.J. 1966;28(6):517522.

8. Gupta S, Khastgir T, Gupta MP, Sethi KK, Manoharan S. Clinical, Haemodynamic and Echocardiographic study in chronic corpulmonale. JAPI 1989;37(6) 373376.

9. Marvin L. Murphy, Fred Hutcheson. The electrocardiographic diagnosis of right ventricular hypertrophy in chronic obstructive pulmonary disease. Chest. 1974;65(4):622-627.

10. Millard FJC. The electrocardiogram in chronic lung 
disease. British heart journal 1967;29(1):43-50.

11. Padmavathi and Veena Raizada. Electrocardiogram in chronic corpulmonale. Br Heart J 1972;34(5):658-667.

12. Tandon MK. Correlation of electrocardiographic features with airway obstruction in chronic bronchitis. Chest 63 (2):146-148.

Source of Support: Nil; Conflict of Interest: None

Submitted: 14-08-2018; Accepted: 22-08-2018; Published online: 29-08-2018 